\title{
Analysis of 801 Work-Related Incidents in the Oil and Gas Industry That Occurred Between 2014 and 2016 in 6 Regions
}

\author{
Moahamed Younes El Bouti ${ }^{1} \&$ Mohamed Allouch ${ }^{1}$ \\ ${ }^{1}$ Department of Chemistry, Faculty of Sciences and Technologies of Tangier, Abdelmalek Essaâdi University, \\ Morocco \\ Correspondence: Moahamed Younes El Bouti, Faculty of Sciences and Technologies of Tangier, Abdelmalek \\ Essaâdi University, Ziaten. BP, Tangier, Morocco. Tel: 21-2664-834-965. E-mail: unes00@hotmail.fr
}

Received: March 30, 2017 Accepted: April 10, $2017 \quad$ Online Published: April 25, 2018

doi:10.5539/eer.v8n1p32 URL: https://doi.org/10.5539/eer.v8n1p32

\begin{abstract}
Oil and Gas Industry (OGI) faces a number of evolving and various types of risks and hazards that give rise to serious incidents. To conduct this study 801 incidents reports have been numerically analyzed, evaluated and interpreted. These incidents reports covered various severity levels, which have been occurred in 6 regions across the world, from 2014 to 2016 . The analysis focused on global oil and gas industry.

The study has shown that Occupational Work-related Incidents (OWRIs) occur mostly in October and especially in spring time. In addition, it has pointed out that the region of North America is the most affected area; almost one-third of OWRIs occurs in turbine hall area. Surprisingly, the study also revealed that three-quarters of the OWRIs did not occur in High-Risk Activity (HRA) and half of the incidents took place with no tooling involved. Noticeably, the main recurrent and frequent event was struck against or by (SAoB) that resulted dominantly in slight injuries that required only first aid care, and the most affected body part is the finger by "Cut (Laceration)/ Pinch". The study has confirmed that the hazardous working environment in OGI was the direct cause for half of the OWRIs. However, based on the revealed results, it will be the assumptions that human factors have a crucial impact on the workplace safety and a contributing factor in the incidents. Some control measures were suggested accordingly.
\end{abstract}

Keywords: analysis, control measures, oil and gas industry, occupational work-related incidents

\section{Introduction}

Work-related incidents constitute a social phenomenon and one of the major problems all over the world, despite all the implemented safety control measures in any organization and the improvements in work-related safety which have been known in the last decades, things can still go wrong, and accidents and incidents still do happen. Ignoring H\&S (Health and Safety) of workers cannot be the stepping stones to a good corporate sustainability strategy. The incidents rates have increased alongside the industrial revolution and the rapid globalization of the world. As a result, all sectors suffer from all types of adverse events ranging from deadly incidents to minor injuries at the workplace particularly in a hazardous working environment such as energy, agriculture, fishery and mining.

Statistics show that in every 15 seconds one worker dies from an OWRI, and 153 workers have a work accident. In addition, 6,300 people passed away daily as a result of OWRIs or work-related ill-health. These work accidents affect negatively both the company performance and bottom-line as well as the economic growth (Hämäläinen et al., 2005).

These above-mentioned figures related to the occupational accidents and diseases which are reported and recorded globally do not reflect the real safety record situation of most companies, since there are cases of underreporting, especially in developing countries. So, the real figures are likely to be far higher than the current recorded ones (Nenonen et al., 2010), and a few catastrophic cases of these incidents receive public attention (Hämäläinen et al., 2005)(ILO, 2003).

The figures above indicate the scale of the problem when H\&S not properly managed; the pain and suffering that is experienced by workers who simply go to work to earn their living. Hence this has a massive negative impact not only on the victims, but also on their dependents, families, and friends. 
Occupational incidents and ill-health can significantly have a negative impact on the profitability of the business and, it can lead a plant out of business because OWRIs and diseases cost money. When an accident occurs there will be direct costs which arise directly from the incident itself and indirect costs which arise indirectly as a consequence of the incidents that are more significant (National General Certificate Unit, 2015).

The Oil and Gas Industry plays a crucial role in driving the global economy; it's the cornerstone to growth and production across the nations since it is omnipresence in all sectors, which makes it indispensable (Department of Homeland Security, 2015)(Higgins and Vernadsky, 2013). However, OWRIs catastrophically took place in OGI more than others, and across different countries in different time periods such as in 1982 for natural gas and 1990,1993 and 1995 for Liquefied Petroleum Gas (LPG) (Hirschberg S et al., 1998), between 2002 and 2010 in Turkey (Ünsar and Süt, 2015), between 2006 and 2012 in Iran (Rahmani et al., 2013) between 1970 and 2008 (Burgherr and Hirschberg, 2014).

The main objective of the present work is to address the issue of all OWRIs in the OGI with particular emphasis on the power generation services over 6 regions in the world. The results of the analysis will be exposed in form of quantitative estimations and interpreted in order to provide adequate recommendations and suggestions; hence, the improvement based on revealed results can reduce or eliminate the recurrence and avoid the potential serious harm, injury, or loss from occurring in the forthcoming years in these assessed O\&G companies. This can be achieved through avoiding similar circumstances that are highlighted in this research as it was asserted in the previous study (Drupsteen and Hasle, 2014). Because, when an incident reoccurs in the similar circumstance the outcome may be as bad as or worse than, it was the first time. It's rare to find similar documented studies that highlight global trends and patterns of occupational incidents particularly in the energy sector (Rahmani et al., 2013)(Sanmiquel et al., 2010)(Hämäläinen et al., 2005)(Zhang et al., 2016). Especially in Morocco, there is no study has been conducted on these incident parameters for this sector. Therefore, the outcomes of this study may pave the way and be as a lesson learnt to improve $\mathrm{H} \& \mathrm{~S}$ performance in the existing and the future energy plants in Morocco (Morocco Tomorrow, 2015), and serve as a scientific support to the decision-making process. So that the findings are extremely applicable in Morocco for the following reasons:

- First, the country is coming on new O\&G power plants that will outstandingly go up to be the vast dominant energy supply (48\%) in Morocco by 2030 (Morocco Tomorrow, 2015).

- Second, Moroccan worker will be exposed to new various HRA and hazards, due to the complexity of the converting operation; $70 \%$ of gas from Liquefied Natural Gas (LNG) to install a huge capacity of electricity $(2.4 \mathrm{GW})$.

- Third, Morocco has already been ranked as the first country in the region of the middle eastern crescent as high fatality rate in various types of industries (Hämäläinen et al., 2005).

\section{Materials and Methods}

\subsection{Population Study}

In order to meet the ultimate goal, various activities of OGI across 6 regions in the world including Morocco which have been assessed in this study. In spite of their geographic locations in different parts of the world, they are united by having the same goal which is exploiting oil or gas continuously for energy production. However, 801 of OWRIs occurred during three (3) years from 2014 to 2016 in this assessed sector of activity. All of these work incidents have been recorded and reported which are afterwards analyzed, evaluated and interpreted in this study. Fishbone diagram applied to analyze the causes that lead to incidents based on $3 \mathrm{~W}$ (Work, Worker, Workplace) method.

During this analysis, we will calculate index value based on the reference year 2014, and the OWRIs of the following years will be evaluated according to this reference year. Index numbers represent the amount of change compared to a base value (reference year) so that, each subject value will be divided by the base value multiply the result by 100 to convert it to a percentage of the base value which assists to monitor the changes over the years.

\subsection{Assessed Variables}

The four main variables TLCR are assessed in this study; however, it is designed in the funnel development conception which takes each variable from general to more screening information (sub-variables). 
Step 1: Problem identification : Occupational Work-Related Incident

Step 2: Collection of information (Incidents reports)

Step 3: Analysis and Breakdown the problem (TLCR)

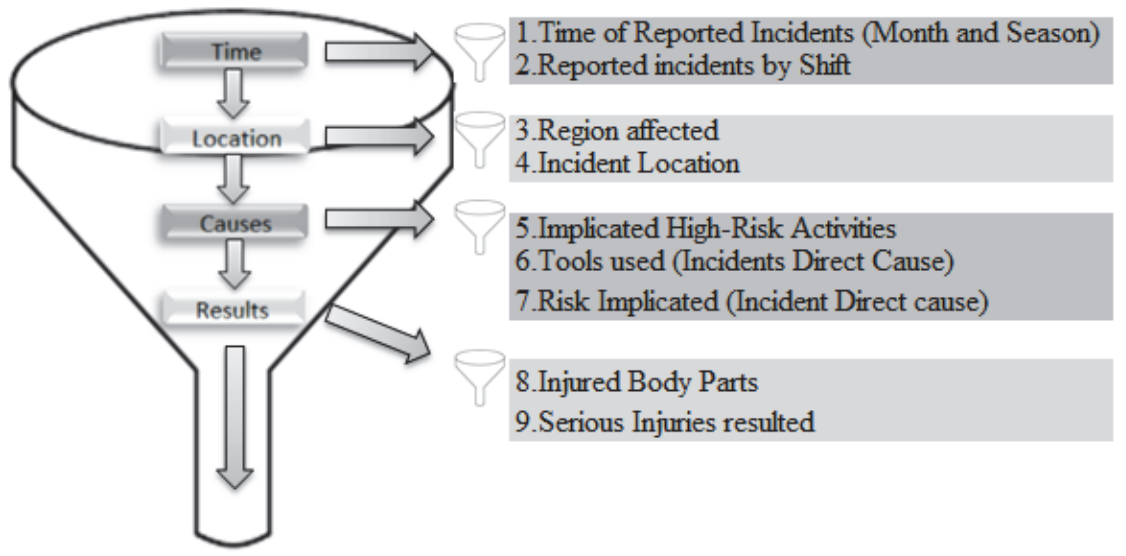

Step 4: Develop countermeasures

Figure 1. Funnel diagram for Occupational Work-Related Incidents analysis in 4 steps

There are 4 variables and 9 sub-variables which have been numerically analyzed, evaluated and interpreted.

These variables and sub-variables have been defined in each single incident report after a detailed investigation of each individual incident, which is first carried out by the investigators at the incident time in the workplace, as well as the corrective and preventive measures that have been implemented in place. Then, a significant effort has been directed towards the examination of these incidents reports to highlight trends and patterns. The outcomes are interpreted as being a result of three main factors; Individual, Job and organization factors, which have an important role in H\&S performance, particularly in a hazardous working environment (Neal and Griffin, 2002)(Zin and Ismail, 2012). To conduct this statistical analysis, the data obtained from incidents reports were tabulated for some selected variables. The most remarkable results will be exposed in this study.

The percentage presenting the proportions of the examined variables is not necessarily related to the index value; this latter highlights the increase and decrease of each individual sub-variable.

\subsection{Hierarchy Used for Recommendations and Suggestions}

Recommendations and suggestions will be based on the merged of accidents causations model (Stein and Heiss, 2015), with Hierarchy of Hazard Control (BSI, 2007), as is shown in figure 3.

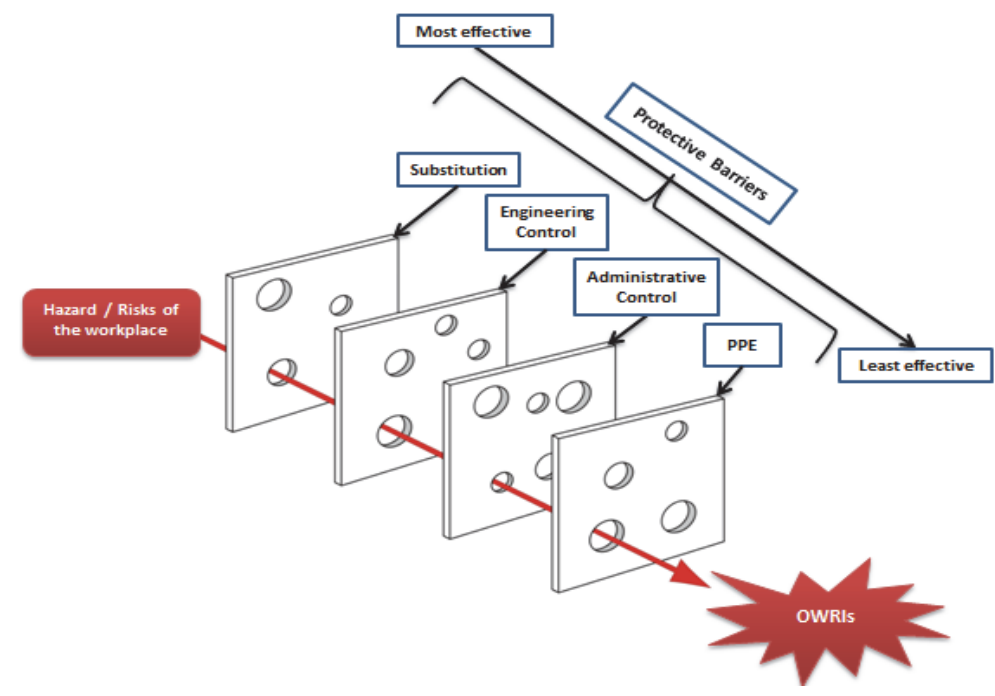

Figure 2. Swiss cheese model of accidents causations 
The holes in the slices represent weaknesses in the organization system and are continually varying in severity size and position across the slices. These slices represent protective barriers which are control options set out as a hierarchy, from most effective (elimination) to the least effective (PPE), then when it fails, it fails to danger. Since the workers are exposed to risk, and may not behave in an ideal way in the workplace; they may break rules deliberately and are subject to human error. Administrative controls and PPE are very reliant on personal behavior and therefore are likely to be the least effective of all of the control options; this is one of the reasons why most work incidents (More than $80 \%$ ) are attributed to unsafe behaviors (Choudhry et al., 2016). Therefore, most of the recommended control measures are focused on last two slices (Administrative controls and PPE).

\section{Results}

\subsection{Classification of the Occurred Work Incidents by the Time of Occurrence}

Table 1. Distribution of 801 reported occupational work-related incidents according to reporting month and season

\begin{tabular}{|c|c|c|c|c|c|c|c|c|c|}
\hline \multirow{2}{*}{\multicolumn{2}{|c|}{ Time of Reported Incidents (Month and Season) }} & \multicolumn{3}{|c|}{ Number of OWRIs } & \multirow[b]{2}{*}{$\%$} & \multirow[b]{2}{*}{\begin{tabular}{|l}
$\begin{array}{l}\text { Total } \\
(\%)\end{array}$ \\
\end{tabular}} & \multicolumn{3}{|c|}{ Index Value } \\
\hline & & \multirow{2}{*}{\begin{tabular}{|l|}
2014 \\
2 \\
\end{tabular}} & \multirow{2}{*}{\begin{tabular}{|l|}
2015 \\
21 \\
\end{tabular}} & \multirow{2}{*}{\begin{tabular}{|l|}
2016 \\
30
\end{tabular}} & & & 2014 & 2015 & 2016 \\
\hline \multirow{3}{*}{ Autumn } & September & & & & 6.6 & \multirow{3}{*}{32} & 100 & 1050 & 1500 \\
\hline & October & 4 & 50 & 72 & 15.7 & & 100 & 1250 & 1800 \\
\hline & November & 5 & 29 & 43 & 9.6 & & 100 & 580 & 860 \\
\hline \multirow{3}{*}{ Winter } & December & 3 & 24 & 15 & 5.2 & \multirow{3}{*}{17,2} & 100 & 800 & 500 \\
\hline & \begin{tabular}{|l|} 
January \\
\end{tabular} & 4 & 12 & 20 & 4.5 & & 100 & 300 & 500 \\
\hline & February & 6 & 22 & 32 & 7.5 & & 100 & 366.7 & 533.3 \\
\hline \multirow{3}{*}{ Spring } & March & 11 & 34 & 36 & 10.1 & \multirow{3}{*}{34} & 100 & 309.1 & 327.3 \\
\hline & April & 10 & 53 & 43 & 13.2 & & 100 & 530 & 430 \\
\hline & May & 10 & 34 & 41 & 10.6 & & 100 & 340 & 410 \\
\hline \multirow{3}{*}{ Summer } & June & 3 & 29 & 17 & 6.1 & \multirow{3}{*}{16.9} & 100 & 966.7 & 566.7 \\
\hline & July & 5 & 14 & 28 & 5.9 & & 100 & 280 & 560 \\
\hline & August & 1 & 24 & 14 & 4.9 & & 100 & 2400 & 1400 \\
\hline \multicolumn{2}{|l|}{ Total } & 64 & 346 & 391 & 100 & 100 & 100 & 540.6 & 610.9 \\
\hline \multicolumn{2}{|l|}{ Grand Total } & \multicolumn{3}{|l|}{801} & & & & & \\
\hline
\end{tabular}

The table 1 shows that October is the month when the most of the OWRIs occurred (15.7\%) in OGI across 6 regions. A sharp increase is seen in 2015 and continues increasing in 2016 to become the critical month of the year 2016. April is considered as the second month when most of the incidents (13.2\%) took place. It's noticed that there was a sharp increase of OWRIs in August 2015 almost 24 times more than the reference year and went down significantly in the following year. It has been deduced that October and April are the periods when most OWRIs took place; these incidents might be attributed to some special HRA (beyond the routines tasks) that took place during this period especially for some $O \& G$ plants that shut down to conduct major maintenance of big machines such as gas and steam turbines. During this maintenance outage, the workers are more exposed to incident risks due to the hazardous nature and load of works, which required more labors. Therefore, the risk level increased considerably while contracting interim workers.

The statistics revealed that $34 \%$ of OWRIs happened in Springtime, this high incidents rate might be attributed to the weather factor even if it is not similar in all regions surveyed; during this season the workplace hazards increased in some regions such as wet floors, slippery spot due to heavy precipitation. In other regions, dust and allergens hazard get worst in the spring when pollen is high, workers, therefore with seasonal allergies and asthma often suffer at the workplace where dust and bacteria are difficult to control particularly for the outdoor works such as transportation, lifting and some maintenance tasks. 


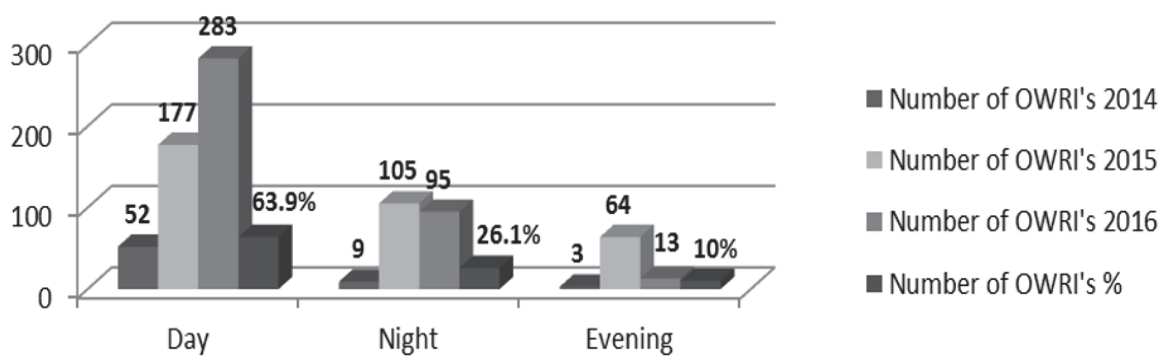

Figure 3. Distribution of 801 reported occupational work-related incidents according to reporting shift

The bar chart of figure 4 shows that approximately two-thirds of the OWRIs (63.9\%) occurred at the day shift whereas only one-third of the OWRIs (36.1\%) happened between night and evening shift. The statistics highlight that the OWRIs rate decreases gradually from $63.9 \%$ in day shift to $10 \%$ in the evening shift. If we consider the scoring system of risk assessment (Safety and Sector, 2013) then, it is clear that this high trend of incidents is related to the magnitude and exposure of the existing risks during the day shift involving the worker, workplace and work nature. The main reasonable explanations grouped in organization factors are:

- All main activities are conducted during day shift or at least the critical ones are carried out during the day shift.

- In some companies no or little work is dedicated to the night shift.

- During the evening shift over change time, there is less risk as there is no work performed.

\subsection{Classification of the Occurred Work Incidents by the Incident Locations}

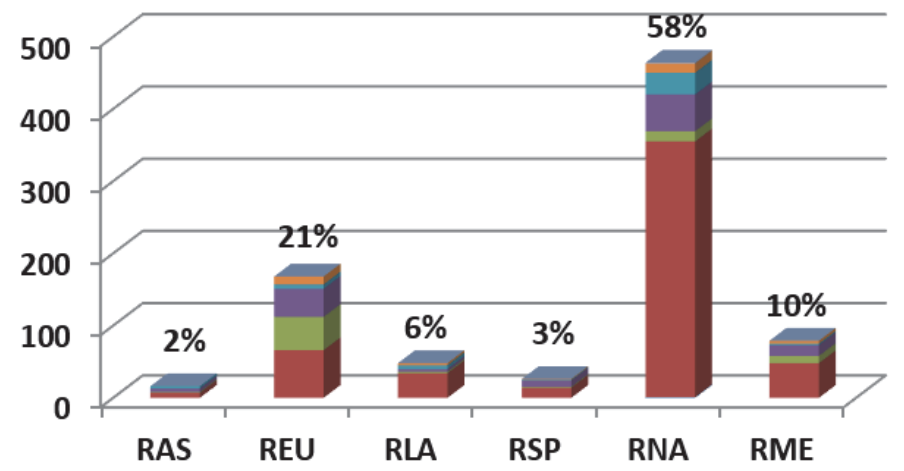

m OI: Occupational ill health

- TA: Travel Accident

- RWI: Restricted Work Injury

- MTC: Medical Treatment Case

LTC: Lost Time Case

- FAC: First Aid Case

-FA: Fatal Accident

Figure 4. Distribution number of occupational work-related incidents in Oil and Gas industry by region

This graph (figure 5) clearly shows that most incidents happen in Region of North America (RNA) by $58 \%$ over the past three years in OGI. The most noteworthy incident category is the FAC, which explains that most of the occurred incidents are less serious incidents which required only first aid treatment. As illustrated in the bar chart (figure 5), Region of United Europe (REU) and RNA are the most affected regions by OWRIs as proved by the results of the previous study (Hirschberg S et al., 1998). Although the two studies agreed on the rate of incidents in the regions, they differ in terms of severity level. The findings of the study (Hirschberg S et al., 1998) were more specific to work-related accidents ( $>5$ fatalities) whereas my study involves other incidents categories. The high incident rate in both regions could be, therefore, attributed to the underreporting (Tucker et al., 2014) particularly in developing countries as it was already asserted in the earlier study (Hämäläinen et al., 2005). This lack of reporting might be due to several reasons such as:

- Fear of reprimand, an assumption that pain is part of the work activity or seniority.

- Fear of losing one's job.

- Different cultural or attitudinal habits as it were referred to in the past research (Celso Salim, 1999).

Obviously, lack of reporting and investigations could eventually lead to serious incidents. 
In the table of appendix A the statistics display two main different outcomes: the first, Turbine hall (29.3\%) is the location where most of the OWRIs occur, this result is consistent with previous studies (Ünsar and Süt, 2015)(Hirschberg S et al., 1998)(Dones et al., 1996). The second incidents scene is the Generator with 9.1\%.

Bearing in mind that the alarming rate $(20.1 \%)$ exhibits unspecified incidents locations since it is not found in the examined incident reports. When the year 2014 is taken as a reference, a striking increase is seen in 2015 in Enclosure as incident location followed by a significant decrease in the following year. Similarly, for Turbine Hall, an important increase is observed in 2015 and maintains the same value in the year 2016. The following graph (Figure 6) is a close examination of the discussed table (Appendix A):

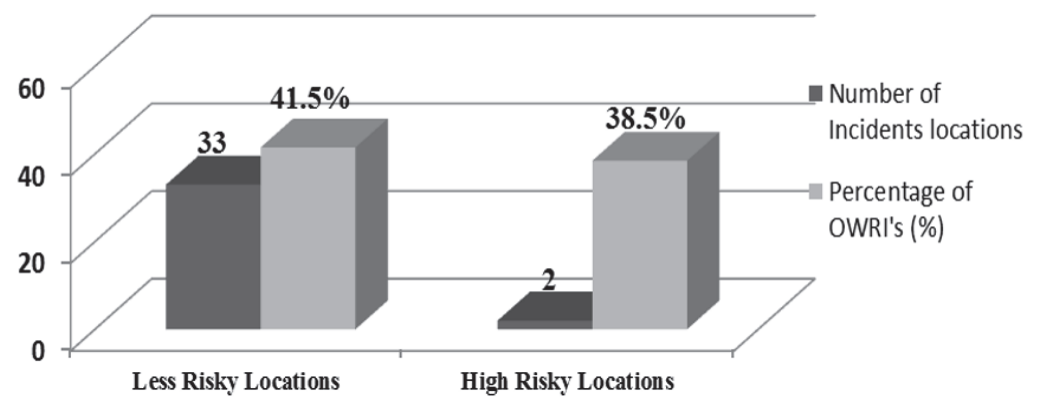

Figure 5. The rate of occupational work-related incidents per number of incident locations

Figure 6 illustrates the criticality of the works nature in these workstations (turbines and generators maintenance or manufacturing). With the exception of the unspecified $20.1 \%$ of the incident locations not included in the graph. Thus, 33 highlighted locations where $41.5 \%$ work-related incidents took place in the past three years, meanwhile, and surprisingly $38.5 \%$ of OWRIs occurred only in 2 locations. As $41.5 \%$ of the incidents locations vary from $0.1 \%$ to $3.7 \%$ overall 33 locations. Thus, it can be said that $33 / 36 \times 100=91.7 \%$ of the locations in OGI are relatively considered less-risky workplaces, and $2 / 36 \times 100=5.6 \%$ of the locations are relatively considered as high-risk workplaces where most of the employees are affected (Turbine Hall and Generator area). It can thus reasonably be assumed that the work duration on turbines and generators is long since it is considered as the core job of the main equipment in the $O \& G$ sector whether manufacturing or providing maintenance service. Therefore, turbine and generator are the most equipment involved in O\&G OWRIs (Ünsar and Süt, 2015)(Hirschberg S et al., 1998).

\subsection{Classification of the occurred work incidents by the relevant causes}

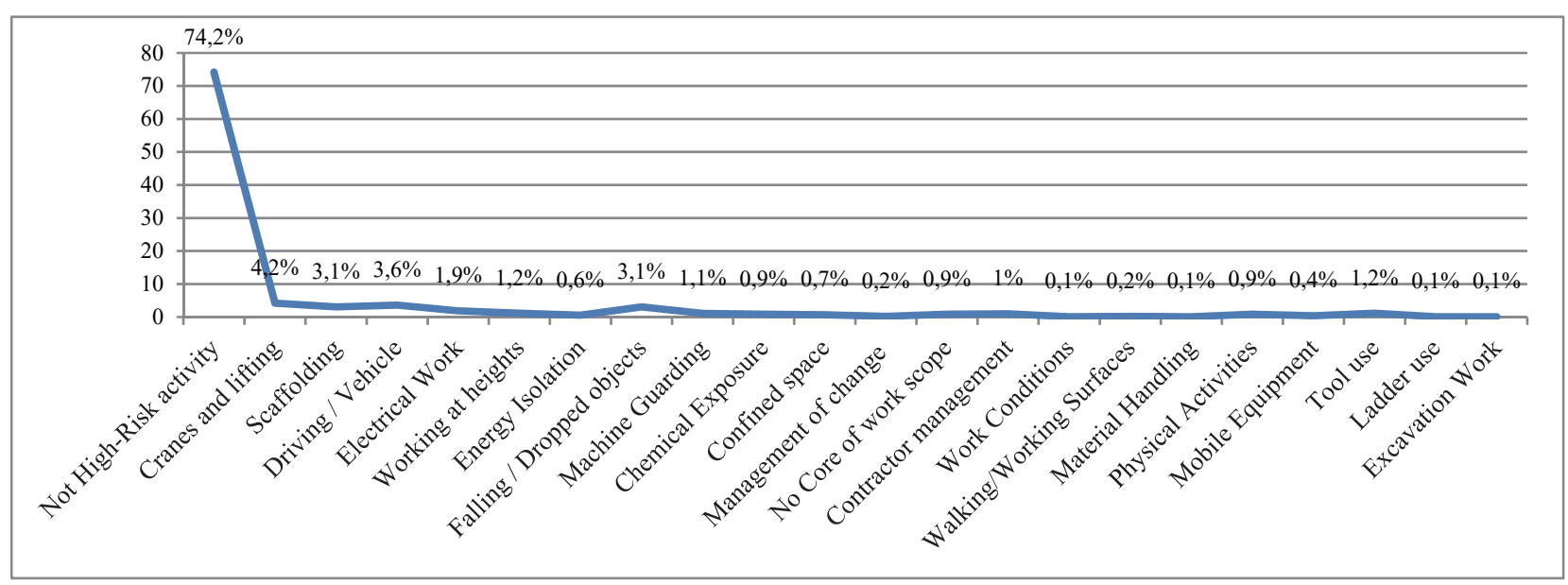

Figure 6. The rate of High-Risk Activities implicated in the OWRIs From 2014 to 2016

The line graph above shows that $74.2 \%$ of the occurred incidents are not during HRA. Unexpectedly in such hazardous industrial sector, the study asserts that different injuries including serious ones arose mainly (74.2\%) from normal activities (non-HRA). Moreover Cranes and lifting operations considered as a first critical task in 
the OGI hence it contributed in $4.2 \%$ of the occurred incidents. The second critical task is driving vehicles which were also caused $3.6 \%$ of OWRIs.

In brief, three-quarters of occurred incidents arose from non-HRA, and the majority are FAC as illustrated previously (figure 4). So, some of the main suggested plausible explanations are:

- Individual factors:

$\Rightarrow$ The overconfidence of experienced employees, which leads to underestimation of the low severity hazards related to non-HRA.

$\Rightarrow$ Poor hazard perceptions for low severity hazards, while giving more intentions to the high severity hazardous tasks (Cranes and lifting).

$\Rightarrow$ The habit of not using PPE (Personal Protective Equipment) for non-HRA.

- Job factors:

$\Rightarrow$ The work nature of non-HRA requires various powered and non-Powered Hand Tools (PHT) that may result in the high rate of non-serious injuries (Cuts, lacerations) as it is reported by Mr. Aghazadeh in 1987 (Aghazadeh and Mital, 1987).

- Organizational factors:

$\Rightarrow$ The implemented safety control measures may be focused on major serious hazards, hence the minor ones remained uncontrolled which give rise to high incident rate from normal activities (Non-HRA). 


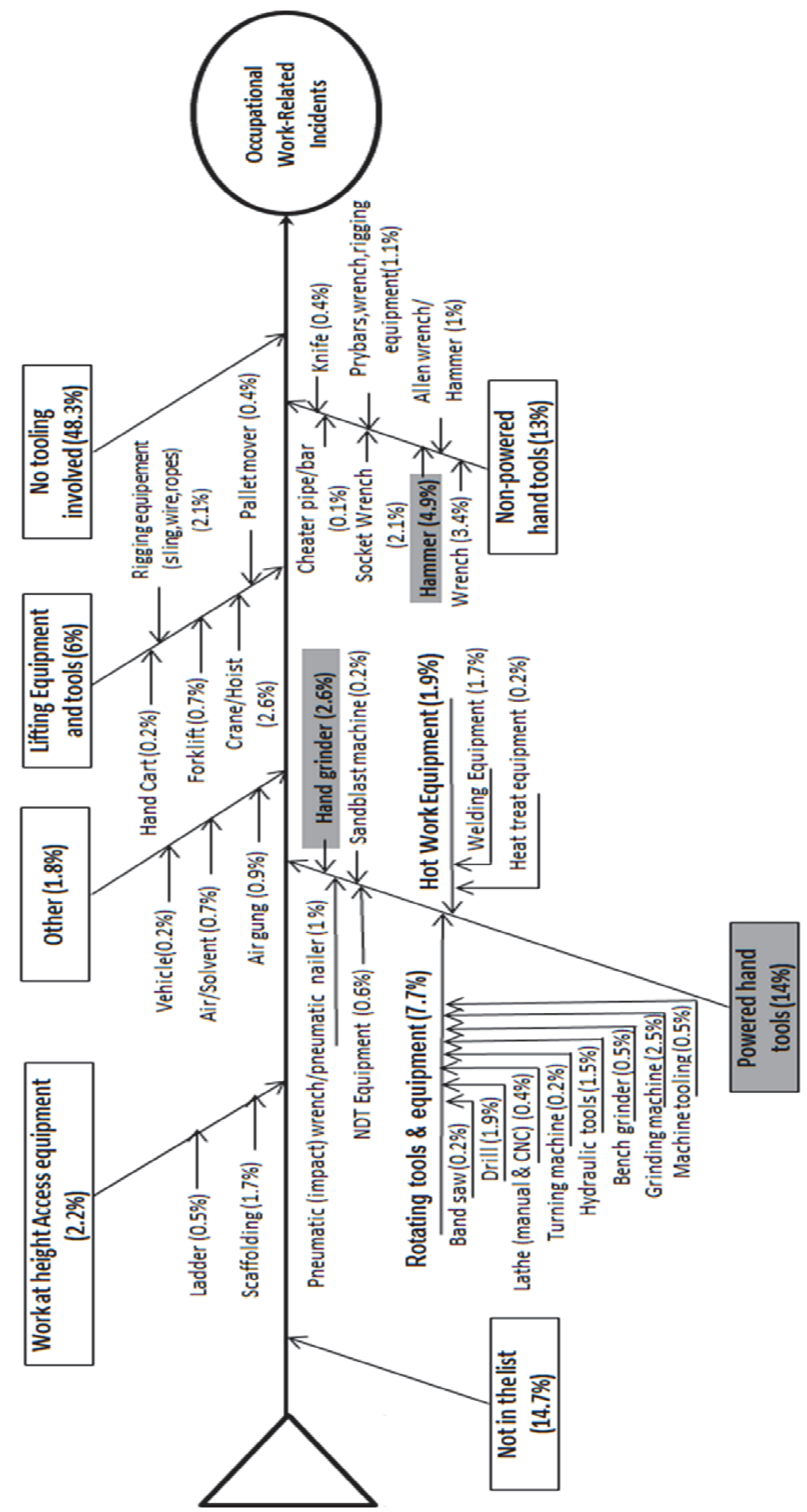

Figure 7. Fishbone diagram of the direct incident cause (Tools used in the workplace)

After the analysis of the cause and effect diagram, startlingly the results unfold that no tooling involved in almost half of the occurred incidents (48.3\%) in the past three years in OGI across 6 regions. An important rate of incidents $(14.7 \%)$ occurred with unspecified tools in safety reporting intranet system. Therefore, some additional specific tools need to be considered by safety practitioners while reporting to have more accurate outcomes. As expected, the hammer was the tool that was mostly present at work $(4.9 \%)$ when the incidents took place. The 
Fishbone Diagram shows clearly tools and equipment categories which are involved in the OWRIs; this categorization remarkably highlights PHTs which are the most involved in the incidents (14\%), which contrasts earlier study (Aghazadeh and Mital, 1987). Hand grinder comes the second tool as it was involved in $2.6 \%$ of the total of OWRIs happened. The high rate of injuries from these both tools types can be attributed to lack of training and awareness regarding manufacturer safety instructions of the used tools as organizational factors.

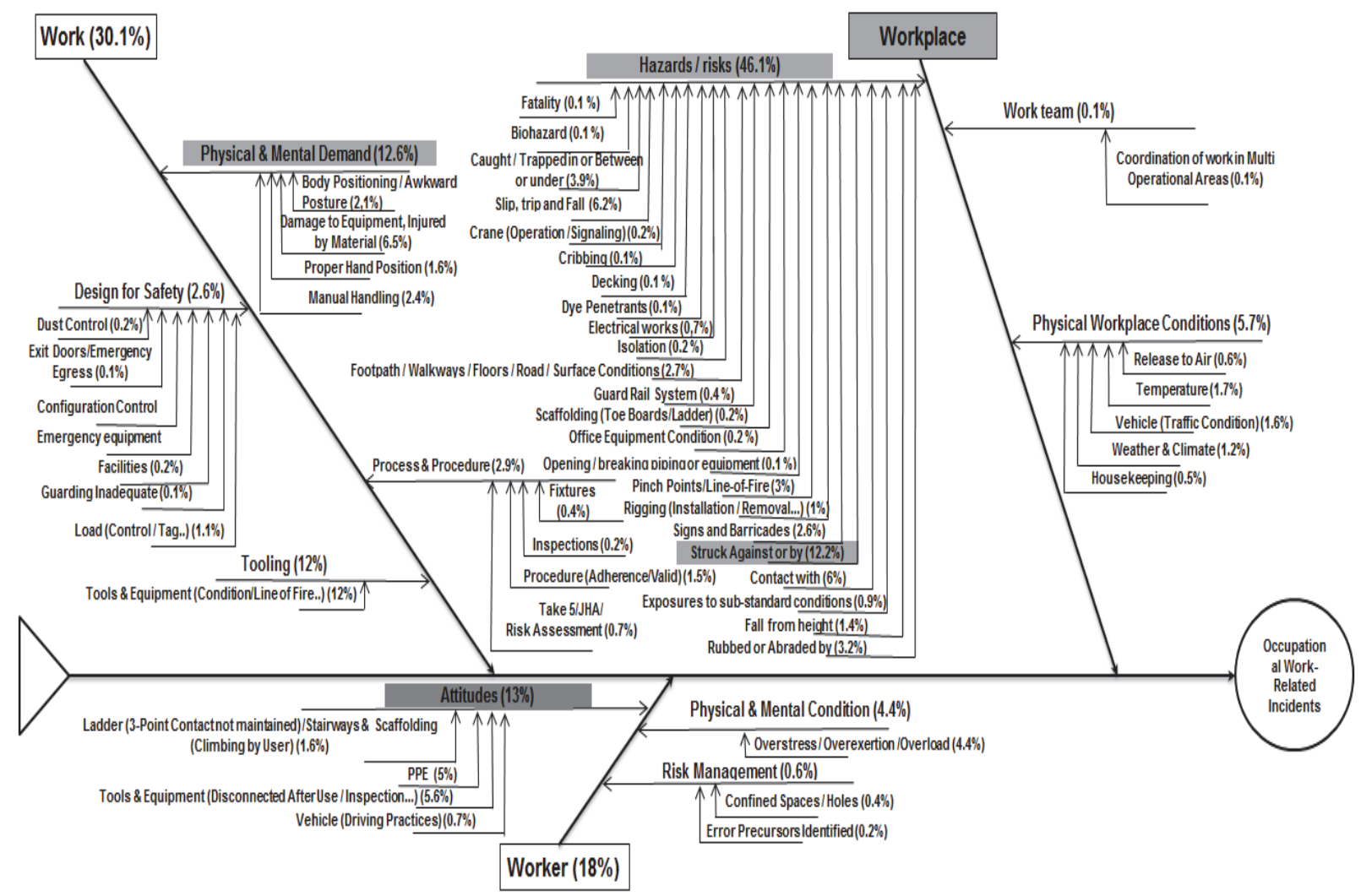

Figure 8. Fishbone diagram of incidents direct causes

The $3 \mathrm{~W}$ method merged with Ishikawa diagram shows clearly the causes of the occurred OWRIs. The results offer compelling vital evidence that the hazardous working environment is a major contributing factor in the occurred OWRIs in OGI. The existing hazards and risks in the workplaces were the direct cause of $46.1 \%$ of the incidents happened, particularly SAoB which is highlighted as the top risk level (12.2\%) among the other existing risks and hazards (Aghazadeh and Mital, 1987). Moreover Struck By was ranked the fifth and Struck Against was ranked sixth as high real direct cost and in 2010 in the United States (Marucci-Wellman et al., 2015). This means that the dominant hazard (SAoB) in OGI is considered higher cost burden related to disabling workplace injuries. Various types of risks in the energy field, lead to emphasize the criticality of the working environment in OGI (Fritzsche, 1989)(Rasmussen, 1981). Work factors were responsible for 30.1\% of the occurred OWRIs. It is noticed that Physical and Mental Demand were the cause of the majority of OWRIs $(12.6 \%)$. The causes which are related to the worker are relatively considered as less serious since they present only $18 \%$ of the occurred OWRIs. Attitude is the most contributing factor (13\%) of the OWRIs cause, as it is confirmed in the previous study (Mearns and Flin, 1995).

\subsection{Classification of the Occurred Work Incidents by the Produced Consequences}

The line graph underneath shows clearly that the most commonly injured body part is the finger, which represents $17.6 \%$ of the total occurred adverse events. The second most frequently affected body part is the hand/wrist (11.9\%). 


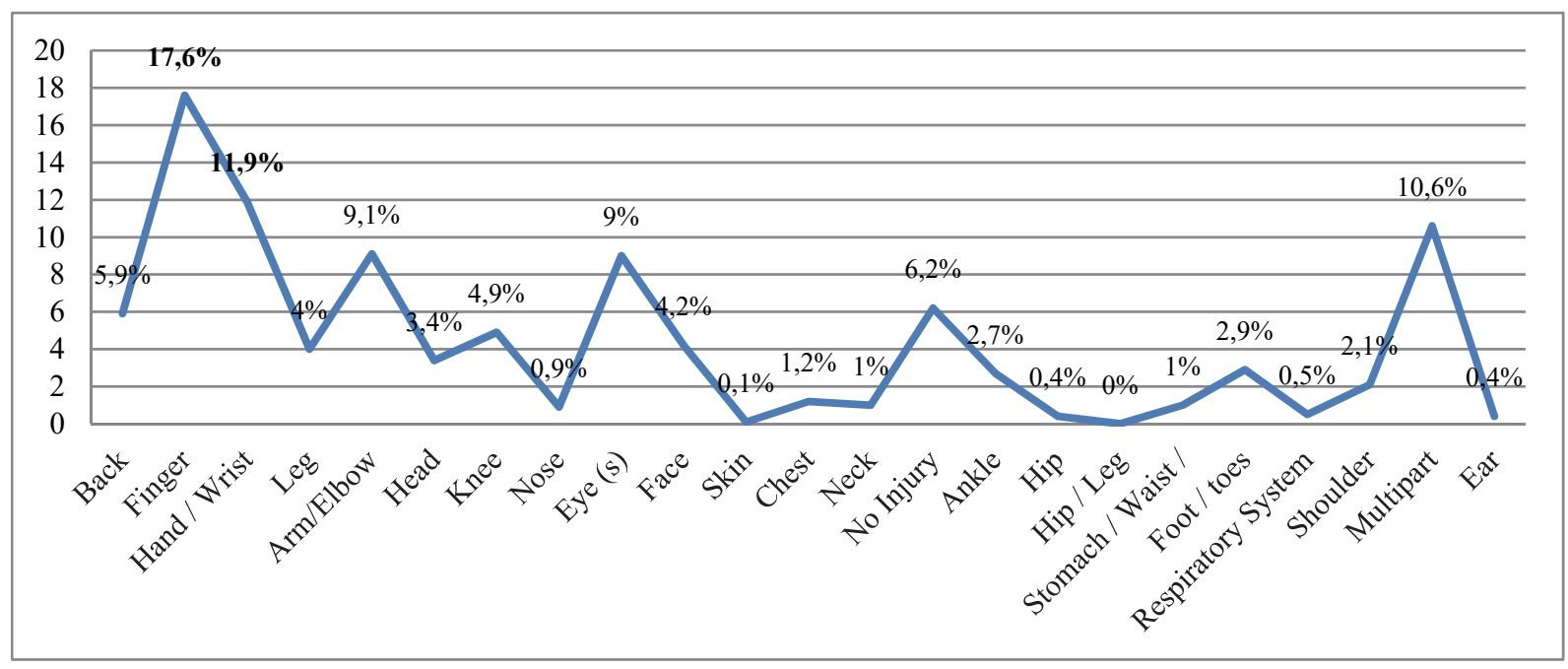

Figure 9. The rate of Injured Body Parts in Oil and Gas Industry From 2014 to 2016

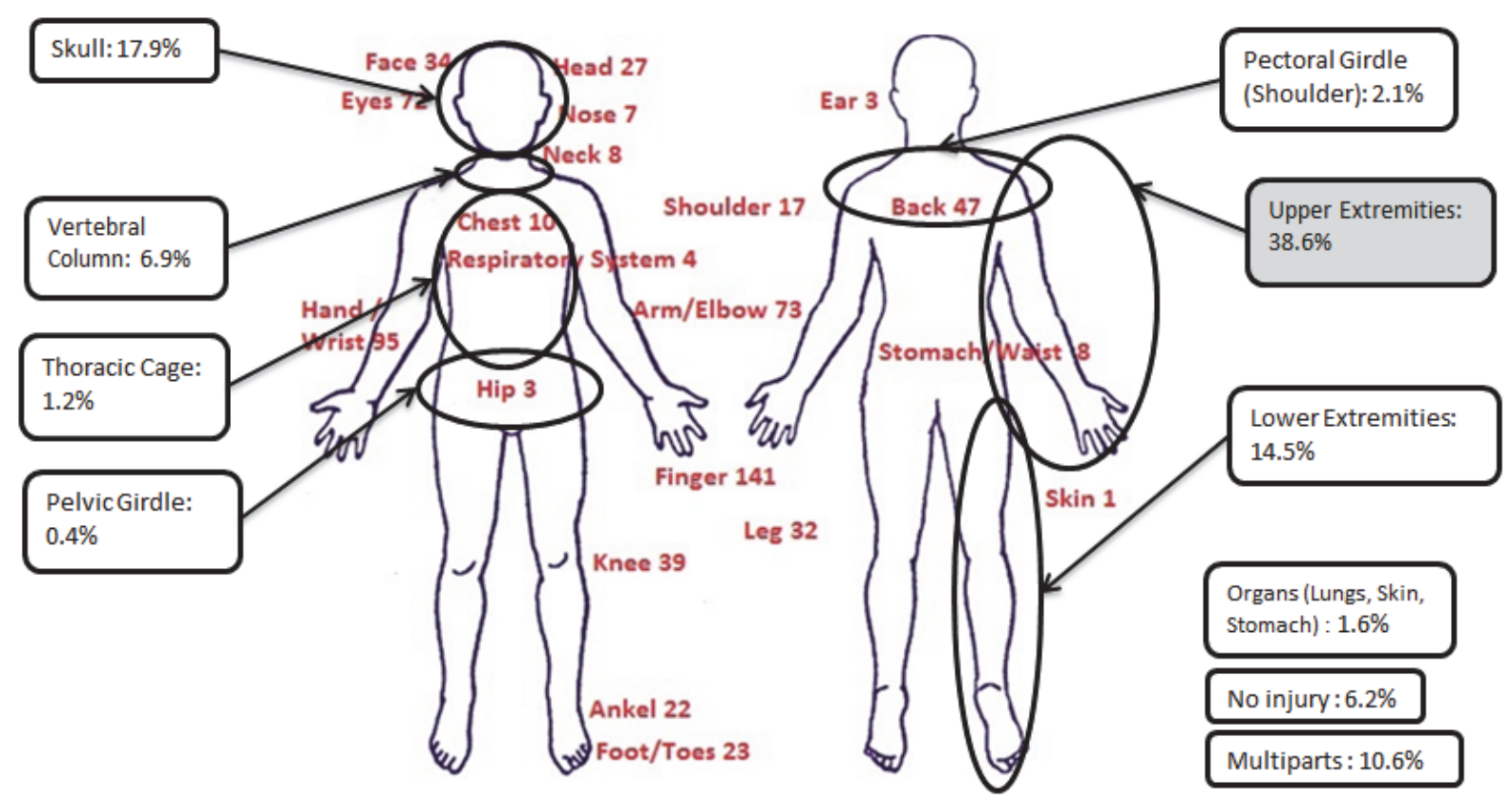

Figure 10. The number and rate of Injured Body Parts

From the figure observed, it noticed that the most affected parts of the body are upper extremities (38.6\%), since the finger, hand/wrist and arm/elbow, were the most injured body parts in the workplace than others. This current study contrasts with what was previously found (Ünsar and Süt, 2015) and substantiates with other past researchers (Aghazadeh and Mital, 1987)(Rahmani et al., 2013).

After the analysis of table in Appendix B, we can say that "Cut (Lacerations)/Pinch" present a quarter (25\%) of the total injuries; that most employees suffered from in the OGI. This result was emphasized in a research conducted by Aghazadeh (Aghazadeh and Mital, 1987). Moreover, an important rate of incidents happened $(19.7 \%)$ and finished in "Bruises/Contusion/Abrasion".

When the year 2014 is taken as a reference, it is noticed that "Sprain and Strains" injuries increased in 2015 almost 12 times and continued increasing lightly in the following year. Furthermore, a small proportion (6.6\%) of incidents results from no injury, and it sharply increased in 2015 almost 6 times more than the base year, and the trend continued increasing significantly in the coming year almost 46 times. 
When it comes to the most serious injuries as illustrated in the table with grey color cases, it is observed that the variation is more or less constant except the "Impact/Crush" injuries, which remarkably increased 11 times in 2015 more than the reference year, and inexplicably went down sharply in 2016.

\section{Discussion}

Our worldwide research study is advanced in current country-focused studies because it will help to highlight trends and patterns globally in O\&G sector, which provides valuable opportunities for improvements in similar workplaces at the global level. Especially in developing countries where incidents rate is higher (Hämäläinen et al., 2005)(Nenonen et al., 2010).

The incidents classification used in this study (Table 4) help to determine the severity level of the analyzed incidents. Thus, this method gives a possibility to prioritize incidents based on their impact situation that causes these incidents on the business. Many previous studies didn't focus on various incidents categories which lead to remain their incidents analysis superficial in terms of focused priority incidents category to be reduced or eliminated. Hence, the number of accidents occurred did not specify the severity level of this latter (Ünsar and Süt, 2015)(Rahmani et al., 2013)(Sanmiquel et al., 2010)(Hämäläinen et al., 2005)(Zhang et al., 2016). Therefore, $t$ is hard to define adequate correctives measures to avoid recurrence of the incidents. Our method has beneficial and useful applications regarding incident severity levels by categorizing them, and which indirectly improve $\mathrm{H} \& \mathrm{~S}$ performance in the workplace while implementing appropriate preventive and correctives measures (Ali et al., 2017). As well as the injury classifications used in this study (Table 6) provide accuracy of the resultant loss. Thus, it can be useful to define the adequate control measures, that reveals clearly in the shortcomings of the previously used methods (Sanmiquel et al., 2010)(Zhang et al., 2016)(Ünsar and Süt, 2015)(Rahmani et al., 2013), which remain considerably ambiguous and called into question with regard to the exact injury raised. It is concluded that the probable immediate causes of the unveiled results that are applicable for all analyzed sub-variables may be attributed to:

- Individual factors:

$\Rightarrow$ Employees do not possess the adequate technical knowledge experience, competency, and training in relation to their works, as well as the existing workplace hazards.

$\Rightarrow$ Poor experience and unfamiliarity with work nature, workplace and used tools, particularly for new recruited workers. This gives rise to slight injuries (FAC) for upper extremities.

$\Rightarrow \quad$ No PPE have been worn.

$\Rightarrow$ Using the wrong tool for the wrong task.

$\Rightarrow$ Negative attitudes and habits of the workers.

- Job factors:

$\Rightarrow$ The workload increases the work pressure that affects negatively safety behavior of the workers (Amponsah-Tawaih and Adu, 2016). This may lead to potential OWRIs (e.g. slight injuries) in the workplace, which requires only first-aid treatment.

- Organizational factors:

$\Rightarrow$ The unresponsiveness of the management to $\mathrm{H} \& \mathrm{~S}$ issues.

$\Rightarrow$ Negative peer group pressure.

$\Rightarrow$ Lack or absence of coordination in the workplace.

$\Rightarrow$ Poor working procedure of the conducted works.

$\Rightarrow$ Lack of supervision.

$\Rightarrow$ Poor safety culture.

$\Rightarrow$ Insufficient budget allocated to purchasing PPE (Rahmani et al., 2013).

$\Rightarrow$ PPE type does not match the nature of the hazard dealt with.

$\Rightarrow$ Uncontrolled workplace hazards; since the study asserts that $46.1 \%$ of occurred OWRIs is due to hazardous working environment (Figure 8).

\section{$\underline{\text { Recommendations and suggestions }}$}

Ensure safety of the workstations machinery equipment and the processes and without risk to health is one of the employer responsibilities (International Labour Organization, 1981). Therefore, accurate recommendations based on revealed results are suggested and set out as a hierarchy, which wasn't considered in past study (Vasconcelos and Junior, 2015).

Elimination:

- Avoid using hammer and PHTs in some selected activities and buy pre-fabricated metal components instead. 
- $\quad$ Eliminate SAoB hazards.

\section{Substitution:}

- In case the hazard cannot be eliminated, it is likely to substitute one hazard with another that creates less risk such as automating some HRA.

Engineering Controls involve the use of engineering solutions will prevent exposure to the hazard such as:

- $\quad$ Barricade all HRA particularly lifting operations in such high risky workplaces (Turbine Hall and Generator area) in order to restrict the working area only for the workers involved in the task.

- $\quad$ Ensure that all PHTs are equipped by a constant pressure switch which shuts off the power upon release.

- Cordon off all foreseeable SAoB hazards and make sure that it inaccessible

Administrative controls are those that rely on procedures and behavior,

- Improve behavior-based safety within the organization by :

$\Rightarrow$ Commitment and leadership from management (Skeepers and Mbohwa, 2015).

$\Rightarrow$ Consultation and worker involvement in the decision- making process, Trainings (Neal and Griffin, 2002).

$\Rightarrow$ Motivations and incentivizing safer behavior (Andriessen, 1978).

- $\quad$ Reduce time of exposure to the high risky workplaces (Turbine Hall and Generator area) and HRA (Crane, Lifting and Driving vehicle). Besides, assign only trained and qualified persons to works in these workstations.

- $\quad$ Conduct regular site inspections by EHS (Environmental Health and Safety) practitioner, in order to:

$\Rightarrow \quad$ Reduce all uncontrolled hazards in the workplaces, particularly SAoB.

$\Rightarrow \quad$ Control workers behavior to reduce OWRIs.

- $\quad$ Provide first aid training to all staffs to improve emergency response effectiveness. This will reduce MTC.

- $\quad$ Put in place first aid equipment in all risky workplaces (Turbine Hall and Generator area)

- $\quad$ Develop a safe system of work (formal procedure) that defines the method of working for all HRA.

- $\quad$ Provide information, instruction and training to all concerned workers on related working procedures, all existing hazards in the workplace, and manufacturer recommendations of all used tools particularly non-PHTs.

In some cases, any of the control measures can't be effective to prevent a potential incident, or even if it can, the residual risk in the workplace still remains. Therefore, PPE must be used.

Human factors have a part to play in effective H\&S management. Good H\&S practice often depends on the good behavior of the workers who sometimes do not. The fact that H\&S standards re-affected by worker behavior can be the hardest barrier for maintaining good H\&S performance in a workplace.

\section{Conclusions}

Table 2. Overview of highlighted trends and patterns of the assessed variables

\begin{tabular}{|l|l|l|l|l|}
\hline \multicolumn{2}{|l|}{ Assessed variables } & Highlighted pattern & Rate \\
\hline \multirow{3}{*}{ Time } & 1 & Time of Reported Incidents (Month and Season) & October & $15.7 \%$ \\
\cline { 2 - 5 } & 2 & Reported incidents by Shift & Spring & $34 \%$ \\
\hline \multirow{2}{*}{ Location } & 3 & Region affected & Day & $63.9 \%$ \\
\cline { 2 - 5 } & 4 & Incident Location & Region North America & $58 \%$ \\
\hline \multirow{3}{*}{ Causes } & 5 & Reported Incidents - High-Risk Activities & Turbine Hall & $38.5 \%$ \\
\cline { 2 - 5 } & 6 & Tools used (Incidents Direct Cause) & Not High-Risk Activities & $74.2 \%$ \\
\cline { 2 - 5 } & 7 & Risk Implicated (Incident Direct cause) & No tooling involved & $48.3 \%$ \\
\hline \multirow{3}{*}{ Results } & 8 & Injured Body Parts & Struck Against or by & $12.2 \%$ \\
\cline { 2 - 5 } & 9 & Serious Injuries resulted & Finger & $17.6 \%$ \\
\cline { 2 - 5 } & & Upper Extremities & $38.6 \%$ \\
\hline
\end{tabular}


The table 2 summarizes clearly the trends and patterns of the workplace incidents in OGI. Therefore, we can say that the high rate of OWRIs is a result of a combination between the hazardous working environments in OGI and the other contributing factors (Individual, job and organization factors) previously mentioned in each sub-variable. Moreover, the high rate of first aid treatment took place in very busy and risky workplace (Turbine Hall). The leading cause of this outcome is the fact that work nature of OGI is manual work, which involves more frequently powered and non-PHTs in a day to day business, that increase "Cut (lacerations)/Pinch" injuries to upper extremities, particularly finger, which require only first aid treatment. Since the magnitude of consequences of the adverse event, is highly dependent on accident cause and other accident characteristics, as it asserted by Robert in 2008 (Restrepo et al., 2009).

\section{Acknowledgements}

I would like to thank all the participants of the anonymous O\&G organization for their contribution to this research and for their openness, hints, and continuous support and assistance, as well as the reviewers who help in improving this paper.

\section{References}

Abu-Khader, M. M. (2004). Impact of Human Behaviour on Process Safety Management in Developing Countries. Process Saf. Environ. Prot., 82, 431-437. https://doi.org/10.1205/psep.82.6.431.53206

Aghazadeh, F., \& Mital, A. (1987). Injuries due to handtools. Results of a questionnaire. Appl. Ergon., 18, 273-278. https://doi.org/10.1016/0003-6870(87)90134-7

Ali, M., Nebhwani, M., Khatri, A., \& Bux, H. (2017). An assessment of occupational health and safety measures and performance of SMEs: An empirical investigation. Saf. Sci., 93, 127-133. https://doi.org/10.1016/j.ssci.2016.11.024

Amponsah-Tawaih, K., \& Adu, M. A. (2016). Work Pressure and Safety Behaviors among Health Workers in Ghana: The Moderating Role of Management Commitment to Safety. Saf. Health Work, 7, 340-346. https://doi.org/10.1016/j.shaw.2016.05.001

Andriessen, J. H. T. H. (1978). Safe behaviour and safety motivation. J. Occup. Accid., 1, 363-376. https://doi.org/10.1016/0376-6349(78)90006-8

Borg, B. (2002). Predictive Safety from Near Miss and Hazard Reporting. Bernard Borg, 1-17.

BSI British Standards Institution. (2007). OHSAS 18001:2007 Occupational Health And Safety Management Systems - Requirements. 1. Ed. .: OHSAS Project Group - British Standards Institution, 34p.

Burgherr, P., \& Hirschberg, S. (2014). Comparative risk assessment of severe accidents in the energy sector. Energy Policy, 74, S45 - S56. https://doi.org/10.1016/j.enpol.2014.01.035

Burgherr, P., Eckle, P., \& Hirschberg, S. (2012). Comparative assessment of severe accident risks in the coal, oil and natural gas chains. Reliab. Eng. Syst. Saf., 105, 97-103. https://doi.org/10.1016/j.ress.2012.03.020

Celso Salim. (1999). Analysis of work related accidents in the Spanish mining sector from 1982-2006. J. Safety Res., 42, 171-182. https://doi.org/10.1016/j.jsr.2009.09.008

Chang, J. I., \& Lin, C. C. (2006). A study of storage tank accidents. J. Loss Prev. Process Ind., 19, 51-59. https://doi.org/10.1016/j.jlp.2005.05.015

Choudhry, R. M., Fang, D., \& Mohamed, S. (2016). Developing a Model of Construction Safety Culture. J. Manag. Eng., 23, 7. https://doi.org/10.1061/(ASCE)0742-597X(2007)23:4(207)

Department of Homeland Security. (2015). Energy Sector-Specific Plan.

Dones, R., Gantner, U., Hirschberg, S., Doka, G., \& Knoepfel, I. (1996). Project GaBE (Comprehensive Assessment of Energy Systems): C. PAUL SCHERRER Inst., 27, 147.

Drupsteen, L., \& Hasle, P. (2014). Why do organizations not learn from incidents? Bottlenecks, causes and conditions for a failure to effectively learn. Accid. Anal. Prev., 72, 351-358. https://doi.org/10.1016/j.aap.2014.07.027

Fritzsche, A. F. (1989). The Health Risks of Energy Production. Wiley Online Libr., 9, 565-577. https://doi.org/10.1111/j.1539-6924.1989.tb01267.x

Hämäläinen, P., Takala, J., \& Saarela, K. L. (2005). Global estimates of occupational accidents. Saf. Sci., 44, 137-156. https://doi.org/10.1016/j.ssci.2005.08.017 
Health and Safety Executive. (2017). Poor housekeeping causes trip accident - Slips and trips - HSE. Heal. Saf. Exec. Retrieved from www.hse.gov.uk/slips/experience/poorhouskeeping.htm (accessed 7.16.17).

Higgins, B. K. L., \& Vernadsky, V. (2013). Economic growth and sustainability - are they mutually exclusive? Elsevier.

Hirschberg, S., Spiekerman, G., \& Dones, R. (1998). Severe Accidents in the Energy Sector First edition. PAUL SCHERRER Inst. 469.

ILO. (1981). Convention C155 - Occupational Safety and Health Convention, 1981 (No. 155). ILO.

ILO. (2003). Safety in numbers - Pointers for global safety culture at work. Br. J. Surg. 1-33.

Marucci-Wellman, H. R., Courtney, T. K., Corns, H. L., Sorock, G. S., Webster, B. S., Wasiak, R., Noy, Y. I., Matz, S., \& Leamon, T. B. (2015). The direct cost burden of 13 years of disabling workplace injuries in the U.S. (1998-2010): Findings from the Liberty Mutual Workplace Safety Index. J. Safety Res., 55, 53-62. https://doi.org/10.1016/j.jsr.2015.07.002

Mearns, K., \& Flin, R. (1995). Risk perception and attitudes to safety by personnel in the offshore oil and gas industry: a review. J. Loss Prev. Process Ind., 8, 299-305. https://doi.org/10.1016/0950-4230(95)00032-V

Morocco Tomorrow. (2015). Morocco Aims High With LNG And Power Plants. Retrieved from http://www.moroccotomorrow.org/morocco-aims-high-with-lng-and-power-plans/ (accessed 6.1.17).

National General Certificate Unit. (2015). NEBOSH Certificate Courses - Sample Material, national examination board in occupational safety and health. national examination board in occupational safety and health, London, United Kingdom. https://doi.org/10.1016/B978-0-08-097070-7

Neal, A., \& Griffin, M. A. (2002). Safety Climate and Safety Behaviour. Aust. J. Manag. Aust. Grad. Sch. Manag. Spec., 27, 67-75. https://doi.org/10.1177/031289620202701S08

Nenonen, N., Saarela, K. L., Takala, J., \& Hämäläinen, P. (2010). Global Estimates of Occupational Accidents and Fatal Work-Related Illness. Uma ética para quantos, XXXIII, 81-87. https://doi.org/10.1007/s13398-014-0173-7.2

Rahmani, A., Khadem, M., Madreseh, E., Aghaei, H. A., Raei, M., \& Karchani, M. (2013). Descriptive study of occupational accidents and their causes among electricity distribution company workers at an eight-year period in Iran. Saf. Health Work, 4, 160-165. https://doi.org/10.1016/j.shaw.2013.07.005

Rasmussen, N. C. (1981). The Application of Probabilistic Risk Assessment Techniques to Energy Technologies. Annu. Rev., 6, 123-138. https://doi.org/10.1146/annurev.eg.06.110181.001011

Restrepo, C. E., Simonoff, J. S., \& Zimmerman, R. (2009). Causes, cost consequences, and risk implications of accidents in US hazardous liquid pipeline infrastructure. Int. J. Crit. Infrastruct. Prot., 2, 38-50. https://doi.org/10.1016/j.ijcip.2008.09.001

Safety, P., \& Sector, A. H. (October 2013). Risk Assessment Tool and Guidance (Including guidance on application ). Heal. Saf. Exec. 11.

Sanmiquel, L., Freijo, M., Edo, J., \& Rossell, J. M. (2010). Analysis of work related accidents in the Spanish mining sector from 1982-2006. J. Safety Res., 41, 1-7. https://doi.org/10.1016/j.jsr.2009.09.008

Skeepers, N. C., \& Mbohwa, C. (2015). A Study on the Leadership Behaviour, Safety Leadership and Safety Performance in the Construction Industry in South Africa. Procedia Manuf, 4, 10-16. https://doi.org/10.1016/j.promfg.2015.11.008

Stein, J. E., \& Heiss, K. (2015). The Swiss cheese model of adverse event occurrence-Closing the holes. Semin. Pediatr. Surg., 24, 278-282. https://doi.org/10.1053/j.sempedsurg.2015.08.003

Taylor, M. J., Cigularov, K. P., Sampson, J. M., Rosecrance, J. C., \& Chen, P. Y. (2013). Construction workers' reasons for not reporting work-related injuries: An exploratory study. Int. J. Occup. Saf. Ergon., 19, 97-105. https://doi.org/10.1080/10803548.2013.11076969

Thepaksorn, P., \& Pongpanich, S. (2014). Occupational injuries and illnesses and associated costs in Thailand. Saf. Health Work, 5, 66-72. https://doi.org/10.1016/j.shaw.2014.04.001

Tucker, S., Diekrager, D., Turner, N., \& Kelloway, E. K. (2014). Work-related injury underreporting among young workers: Prevalence, gender differences, and explanations for underreporting. J. Safety Res., 50, 67-73. https://doi.org/10.1016/j.jsr.2014.04.001 
Ünsar, A. S., \& Süt, N. (2015). Occupational Accidents in the Energy Sector: Analysis of Occupational Accidents that Occurred in Thermal and Hydroelectric Centrals Between 2002 and 2010 in Turkey. Procedia - Soc. Behav. Sci., 181, 388-397. https://doi.org/10.1016/j.sbspro.2015.04.901

Vasconcelos, B., \& Junior, B. B. (2015). The Causes of Work Place Accidents and their Relation to Construction Equipment Design. Procedia Manuf., 3, 4392-4399. https://doi.org/10.1016/j.promfg.2015.07.437

Zhang, Y., Shao, W., Zhang, M., Li, H., Yin, S., \& Xu, Y. (2016). Analysis 320 coal mine accidents using structural equation modeling with unsafe conditions of the rules and regulations as exogenous variables. Accid. Anal. Prev., 13, 189-201. https://doi.org/10.1016/j.aap.2016.02.021

Zin, S. M., \& Ismail, F. (2012). Employers' Behavioural Safety Compliance Factors toward Occupational, Safety and Health Improvement in the Construction Industry. Procedia - Soc. Behav. Sci., 36, 742-751. https://doi.org/10.1016/j.sbspro.2012.03.081

\section{Appendix A}

Distribution of 801 reported occupational work-related incidents according to Incident Location

\begin{tabular}{|c|c|c|c|c|c|c|c|c|}
\hline \multirow{2}{*}{\multicolumn{2}{|c|}{ Incident Location }} & \multicolumn{3}{|c|}{ Number of OWRIs } & \multirow{3}{*}{\begin{tabular}{|l|}
$\%$ \\
20.1 \\
\end{tabular}} & \multicolumn{3}{|c|}{ Index Value } \\
\hline & & \multirow{2}{*}{\begin{tabular}{|l|}
2014 \\
20
\end{tabular}} & \multirow{2}{*}{\begin{tabular}{|l|}
2015 \\
61
\end{tabular}} & \multirow{2}{*}{\begin{tabular}{|l|}
2016 \\
80
\end{tabular}} & & \multirow{2}{*}{$\frac{2014}{100}$} & \multirow{2}{*}{\begin{tabular}{|l|}
2015 \\
305.0
\end{tabular}} & \multirow{2}{*}{$\begin{array}{l}2016 \\
400,0\end{array}$} \\
\hline 1 & Is not on the list & & & & & & & \\
\hline 2 & Access roads & 2 & 7 & 14 & 2.9 & 100 & 350.0 & 700,0 \\
\hline 3 & Air intake & 0 & 1 & 0 & 0.1 & 100 & 0.0 & 0,0 \\
\hline 4 & Balancing & 0 & 1 & 0 & 0.1 & 100 & 0.0 & 0.0 \\
\hline 5 & Basement & 0 & 1 & 3 & 0.5 & 100 & 0.0 & 0.0 \\
\hline 6 & Blades & 3 & 2 & 4 & 1.1 & 100 & 66.7 & 133.3 \\
\hline 7 & Bolt Cleaning area & 0 & 7 & 7 & 1.7 & 100 & 0.0 & 0.0 \\
\hline 8 & Canteen/Cafeteria & 0 & 1 & 0 & 0.1 & 100 & 0.0 & 0.0 \\
\hline 9 & Combustor & 5 & 10 & 16 & 3.9 & 100 & 200.0 & 320.0 \\
\hline 10 & Components & 0 & 2 & 0 & 0.2 & 100 & 0.0 & 0.0 \\
\hline 11 & Compressor & 4 & 8 & 5 & 2.1 & 100 & 200.0 & 125.0 \\
\hline 12 & Enclosure & 1 & 19 & 10 & 3.7 & 100 & 1900.0 & 1000.0 \\
\hline 13 & exhaust channel & 0 & 6 & 2 & 1.0 & 100 & 0.0 & 0.0 \\
\hline 14 & Hanger & 0 & 1 & 0 & 0.1 & 100 & 0.0 & 0.0 \\
\hline 15 & Generator & 6 & 33 & 34 & 9.1 & 100 & 550.0 & 566.7 \\
\hline 16 & Heavy Machining & 0 & 1 & 1 & 0.2 & 100 & 0.0 & 0.0 \\
\hline 17 & Loading Dock & 1 & 3 & 3 & 0.9 & 100 & 300.0 & 300.0 \\
\hline 18 & Maintenance Shop & 0 & 4 & 3 & 0.9 & 100 & 0.0 & 0.0 \\
\hline 19 & Material lay down area & 1 & 7 & 22 & 3.7 & 100 & 700.0 & 2200.0 \\
\hline 20 & Material Storage Area & 0 & 5 & 2 & 0.9 & 100 & 0.0 & 0.0 \\
\hline 21 & Mechanical Assembly & 0 & 3 & 0 & 0.4 & 100 & 0.0 & 0.0 \\
\hline 22 & Non-destructive testing & 1 & 3 & 12 & 2.0 & 100 & 300.0 & 1200.0 \\
\hline 23 & Office area & 0 & 2 & 7 & 1.1 & 100 & 0.0 & 0.0 \\
\hline 24 & Platform & 1 & 3 & 7 & 1.4 & 100 & 300.0 & 700.0 \\
\hline 25 & Restroom & 0 & 2 & 4 & 0.7 & 100 & 0.0 & 0.0 \\
\hline 26 & Rotor & 1 & 5 & 5 & 1.4 & 100 & 500.0 & 500.0 \\
\hline 27 & Shared area / IP Area & 0 & 1 & 0 & 0.1 & 100 & 0.0 & 0.0 \\
\hline 28 & Shipping/Packing Area & 1 & 1 & 0 & 0.2 & 100 & 100.0 & 0.0 \\
\hline 29 & Stairs & 3 & 2 & 7 & 1.5 & 100 & 66.7 & 233.3 \\
\hline 30 & Tool Room & 0 & 1 & 2 & 0.4 & 100 & 0.0 & 0.0 \\
\hline 31 & Turbine Hall & 11 & 112 & 112 & 29.3 & 100 & 1018.2 & 1018.2 \\
\hline 32 & Vacuum Chamber & 0 & 1 & 0 & 0.1 & 100 & 0.0 & 0.0 \\
\hline 33 & Store & 1 & 11 & 7 & 2.4 & 100 & 1100.0 & 700.0 \\
\hline 34 & Workshop & 0 & 10 & 12 & 2.7 & 100 & 0.0 & 0.0 \\
\hline 35 & Welding Area & 2 & 6 & 3 & 1.4 & 100 & 300.0 & 150.0 \\
\hline 36 & Parking & 0 & 3 & 7 & 1.2 & 100 & 0.0 & 0.0 \\
\hline \multicolumn{2}{|c|}{ Total } & 64 & 346 & 391 & 100 & 100 & 540.63 & 610.94 \\
\hline \multicolumn{2}{|c|}{ Grand total } & 801 & & & & & & \\
\hline
\end{tabular}




\section{Appendix B}

Distribution of 801 reported occupational work-related incidents according to Serious Injuries resulted

\begin{tabular}{|c|c|c|c|c|c|c|c|c|}
\hline \multirow{2}{*}{\multicolumn{2}{|c|}{ Serious Injuries resulted }} & \multicolumn{3}{|c|}{ Number of OWRIs } & \multirow{3}{*}{$\begin{array}{l}\% \\
1.1\end{array}$} & \multicolumn{3}{|c|}{ Index Value } \\
\hline & & \multirow{2}{*}{\begin{tabular}{|l|}
2014 \\
4 \\
\end{tabular}} & \multirow{2}{*}{$\begin{array}{l}2015 \\
2\end{array}$} & \multirow{2}{*}{$\begin{array}{l}2016 \\
3\end{array}$} & & \multirow{2}{*}{$\begin{array}{l}2014 \\
100\end{array}$} & \multirow{2}{*}{\begin{tabular}{|l}
2015 \\
50 \\
\end{tabular}} & \multirow{2}{*}{\begin{tabular}{|l|}
2016 \\
75 \\
\end{tabular}} \\
\hline 1 & Electrical Shock & & & & & & & \\
\hline 2 & Bone Fracture & 4 & 4 & 5 & 1.6 & 100 & 100 & 125 \\
\hline 3 & Ergonomic Injury & 0 & 3 & 0 & 0.4 & 100 & 0 & 0 \\
\hline 4 & Impact / crush & 2 & 21 & 21 & 5.5 & 100 & 1050 & 1050 \\
\hline 5 & Amputation & 1 & 0 & 0 & 0.1 & 100 & 0 & 0 \\
\hline 6 & Burn (Scald/Heat) & 1 & 11 & 4 & 2.0 & 100 & 1100 & 400 \\
\hline 7 & Other & 7 & 16 & 0 & 2.9 & 100 & 228.6 & 0 \\
\hline 8 & Bruise/Contusion/Abrasion & 19 & 71 & 68 & 19.7 & 100 & 373.7 & 357.9 \\
\hline 9 & Burn (Chemical) & 0 & 1 & 0 & 0.1 & 100 & 0 & 0 \\
\hline 10 & Cut (Laceration)/Pinch & 16 & 82 & 102 & 25.0 & 100 & 512.5 & 637.5 \\
\hline 11 & Dislocation & 0 & 1 & 3 & 0.5 & 100 & 0 & 0 \\
\hline 12 & Exposure to Dust/Mist/Fumes & 1 & 4 & 0 & 0.6 & 100 & 400 & 0 \\
\hline 13 & Exposure to UV/welding process & 0 & 1 & 0 & 0.1 & 100 & 0 & 0 \\
\hline 14 & Exposure to Chemicals & 0 & 2 & 0 & 0.2 & 100 & 0 & 0 \\
\hline 15 & Foreign Body & 3 & 14 & 24 & 5.1 & 100 & 466.7 & 800 \\
\hline 16 & Puncture & 0 & 8 & 0 & 1.0 & 100 & 0 & 0 \\
\hline 17 & Insect or animal bite & 0 & 14 & 12 & 3.2 & 100 & 0 & 0 \\
\hline 18 & Heat Exhaustion/Heat Stroke & 0 & 5 & 5 & 1.2 & 100 & 0 & 0 \\
\hline 19 & Irritation / Exposure to hazardous atmosphere & 0 & 11 & 15 & 3.2 & 100 & 0 & 0 \\
\hline 20 & Sprain/Strain & 5 & 59 & 66 & 16.2 & 100 & 1180 & 1320 \\
\hline 21 & Puncture & 0 & 9 & 5 & 1.7 & 100 & 0 & 0 \\
\hline 22 & No Injury & 1 & 6 & 46 & 6.6 & 100 & 600 & 4600 \\
\hline 23 & Concussion / Brain Injury Cut (Laceration)/Pinch & 0 & 1 & 1 & 0.2 & 100 & 0 & 0 \\
\hline 24 & Inflammation & 0 & 0 & 6 & 0.7 & 100 & 0 & 0 \\
\hline 25 & Nausea & 0 & 0 & 3 & 0.4 & 100 & 0 & 0 \\
\hline 26 & Rupture & 0 & 0 & 2 & 0.2 & 100 & 0 & 0 \\
\hline Tot & & 64 & 346 & 391 & 100 & 100 & 540.63 & 610.94 \\
\hline Gra & ind total & 801 & & & & & & \\
\hline
\end{tabular}

\section{Copyrights}

Copyright for this article is retained by the author(s), with first publication rights granted to the journal.

This is an open-access article distributed under the terms and conditions of the Creative Commons Attribution license (http://creativecommons.org/licenses/by/4.0/). 